\title{
Epidemiological Study Regarding Extracapsular Fractures of the Proximal Femur in Adults
}

\author{
Teodor Stefan Gheorghevici' ${ }^{1}$ Manuela-Gabi Poroh ${ }^{2}$, Alexandru Filip ${ }^{2}$, Norin Forna ${ }^{2}$, Paul Sirbu ${ }^{2 *}$, Ovidiu Alexa $^{1,2}$ \\ and Bogdan Puha ${ }^{1,2}$ \\ ${ }^{1}$ Department of orthopedics and traumatology, "Sf. Spiridon" County Clinical Emergency Hospital, Iasi, Romania \\ ${ }^{2}$ Grigore T Popa University of Medicine and Pharmacy, Faculty of Medicine, Department of Orthopedics and Traumatology, Romania
}

Submission: May 25, 2020; Published: June 04, 2020

*Corresponding author: Paul Sirbu, Grigore T Popa University of Medicine and Pharmacy, Faculty of Medicine, Department of Orthopedics and Traumatology, 16 Universitatii Str., 700115, Iasi, Romania

Abstract

Introduction: The development of modern society has led to an increase of the life expectancy and, with it, of the incidence of hip fractures in population. These are a public health issue due to their associated morbidity and mortality.

Material and Method: We analyzed retrospectively all the Extracapsular Fractures of the Proximal Femur (EFPF) admitted between December 2019 - January 2017. The inclusion criteria of this study were: adult patients admitted in the Orthopedics Clinic of "St. Spiridon" Emergency Hospital between January 2017 - December 2019, who consented in writing that their personal data be used for scientific purposes.

Results: We identified a number of 945 EFPF patients admitted in Orthopedics Clinic of "St. Spiridon" Emergency Hospital between January 2017 - December 2019. The gender distribution showed a slightly increased percentage of female patients (64.4\%), the sex ration being $1.8 / 1$. The general intrahospital mortality was 4.48\%, 11/708 (1.55\%) operated patients and 24/237 patients who received functional treatment. We failed to identify statistically significant differences regarding the patients' survival on account of sex and diagnosis, the most frequent death belonging to the 80-89 age group.

Conclusion: The number of patients with EFPF in the studied time gap showed a descending tendency, with a better intrahospital survival for surgically treated patients.

Keywords: Epidemiological Study; Intrahospital Survival; Proximal Femur; Extracapsular Fractures

Abbreviations: EFPF: Extracapsular Fractures of the Proximal Femur; UICS - Unique Integrated Computer System; SPSS: Statistical Package for the Social Sciences; IC - confidence interval; AUC- Area Under the Curve; GCOS - General Clinical Observation Sheet; PERTROH: Pertrocantheric Fractures; BAZICERV: Basicervical Fractures; FRAVTROH: Trochanteric Avulsion Fractures; INTERTROH: Inter-Trochanteric Fractures; TROHCOMPLX: Complex Trochanteric Fractures; TROHDIA: Trochanteric - Diaphyseal Fractures

\section{Introduction}

Hip fractures are often associated with low energy traumatisms and a significant bone fragility due to the presence of osteoporosis [1]. To ensure the therapeutic success, their treatment is mostly surgical [2] and postponing it is associated with an increase in mortality and morbidity $[3,4]$. The functional treatment is reserved for those cases when the surgical risk exceeds the potential benefit. There are two main tendencies in the surgical treatment: intramedullary fixation and extra-medullar fixation, both with biomechanical and functional arguments. In particular cases, the hip arthroplasty may constitute a valuable therapeutic option [3].
In Romania, there is a scarcity of epidemiological studies regarding published proximal femur fractures, most of them referring to the population in the Western side of the country [5]. In this study we aimed at conducting an epidemiological analysis of the extracapsular hip fracture cases admitted in Orthopedics Clinic of "St. Spiridon" Emergency Hospital between January 2017 - December 2019.

\section{Material and Methods}

We analyzed retrospectively all the Extracapsular Fractures of the Proximal Femur (EFPF) admitted between December 


\section{Orthopedics and Rheumatology Open Access Journal (OROAJ)}

2019 - January 2017. The inclusion criteria of this study were: adult patients admitted in the Orthopedics Clinic of "St. Spiridon" Emergency Hospital between January 2017 - December 2019, who consented in writing that their personal data be used for scientific purposes. The data were extracted from the Unique Integrated Computer System (UICS) and from the general clinical observation sheets (GCOS) and analyzed using the IBM SPSS Version 18 software (SPSS Inc, Chicago, IL, USA). For the statistical analysis we used both descriptive and analytical methods at a significance threshold of 95\% (IC95\%). Based on the primary indicators we characterized the study lot using statistical indicators of the mean value: arithmetical mean, the median, module, and dispersion indicators: standard deviation, standard error, variation. We used the linear regression $(y=a x+b)$ to show the interdependence of 2 parameters.

\section{Results}

We identified a number of 945 EFPF patients admitted in the Orthopedics Clinic of "St. Spiridon" Emergency Hospital between
January 2017 - December 2019. The gender distribution showed a slightly increased percentage of the female patients $(64.4 \%)$, the sex ration being 1.8/1. The age group distribution showed a frequency peak at the 80-89 age group, both in female (48.5\%) and male $(32.7 \%)$ patients (Figure 1 ). In the study lot, $86.2 \%$ of the patients received surgical treatment and $13.8 \%$ functional treatment. The general intrahospital mortality reached $4.48 \%$, $11 / 708(1.55 \%)$ of operated patients and $24 / 237$ of functionally treated patients $(15,8 \%)$ dying during hospitalization $(\mathrm{p}=0.005)$. The surgical interventions significantly reduced the death rate. With a sensitivity of $82 \%$ and a specificity of $70 \%$, the surgical intervention is a good predictor of survival (AUC $=0,763$; IC95\%: $0,668-0,857)$. The female patients dominated both the group of patients with an unfavorable diagnosis and the group of surviving patients $(68.6 \%$ vs. $63.9 \%$; $=0.569)$. In the cases we studied, most of them came from the rural environment: $64.5 \%$ of the patients with functional treatment; $57.5 \%$ of all operated patients and $60.5 \%$ of all deaths ( $\mathrm{p}=0.856$ ), (Figure 2).

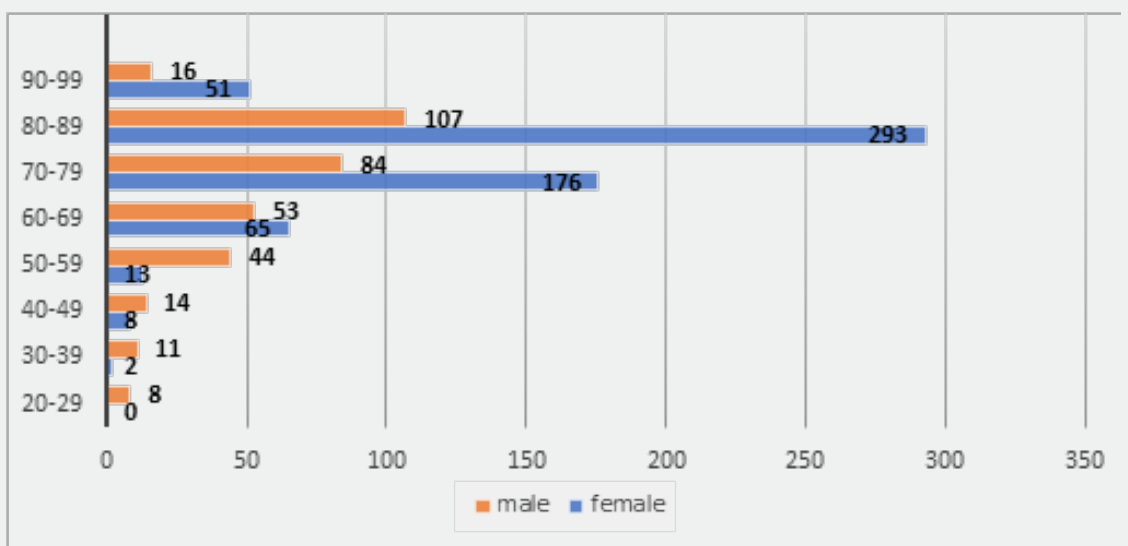

Figure 1: Cohort structure on age groups.

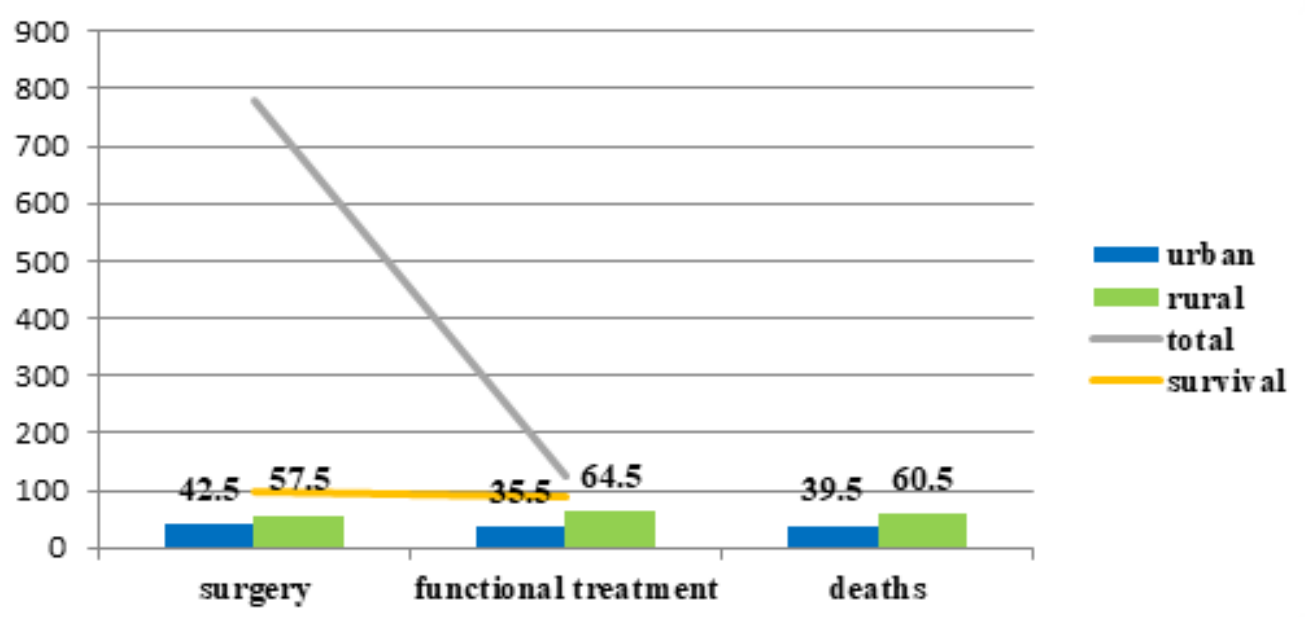

Figure 2: Distribution of the origin environment of patients, depending on the type of treatment and survival. 
For the classification of EFPF we used the descriptive classification. We identified six types of fractures among the patients in the study lot: pertrochanteric fractures (PERTROH), basicervical fractures (BAZICERV), trochanteric avulsion fractures (FRAVTROH), inter-trochanteric fractures (INTERTROH), complex trochanteric fractures (TROHCOMPLX) and diaphyseal trochanteric fractures (TROHDIA). Patients with pertrochanteric fractures dominated (91\%), while inter-trochanteric and avulsion fractures represented the smallest incidence (1\%). In correlation with gender, the percentual distribution depending on the diagnosis registered significant differences $(p=0.018)$ for both genders the highest frequency belonging to pertrochanteric fractures (90.14\% vs $92.26 \%)$, bascervical fractures were best represented among female patients (4.59\% vs $0.89 \%)$ (Figure $3)$. The duration of hospitalization varied between 1 and 49 days, with significant differences of the mean values depending on the diagnosis ( $\mathrm{p}=0.001)$ (Figure 4).

Figure 3: Cohort structure depending on diagnosis and gender distribution.

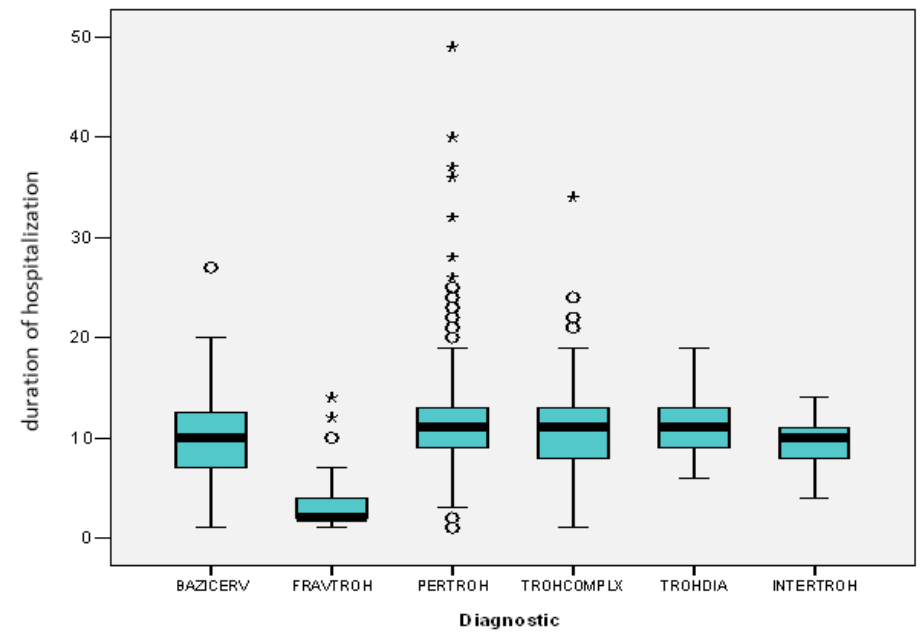

Figure 4: Mean values of the duration of hospitalization depending on the fracture type

The preop period varied from 0 to 19 days, for $56.1 \%$ of the patients a larger preop period being correlated with a longer duration of hospitalization $\left(r=+0.561 ; R^{2}=0.3974 ; p=0.001\right)$. The mean preop period was 7 days $(\mathrm{y}=1.0038 \mathrm{x}+7.1427$, $\mathrm{R}^{2}=0.3974$ ), being correlated with the preop period (Figure 5).

The preop period was significantly lower in deceased patients ( 3.73 vs 4.94 days; $\mathrm{p}=0.05$ ), beside the duration of hospitalization
(10.20 vs 10.96 days; $p=0.380$ ). In this study, we attempted to quantify the intrahospital mortality and the factors influencing it to optimize the treatment of these patients and to increase their life expectancy. Mortality was met in $4.5 \%$ of the cases, with a survival probability under $65 \%$ at 3 years after surgery (Figure 6 ). The mortality rate depending on the diagnosis failed to record significant percentual differences, an aspect also confirmed by the ROC curve (AUC=0.517; IC95\%: 0.422-0.612) (Figure 7). With functionally treated patients, mortality was significantly higher 


\section{Orthopedics and Rheumatology Open Access Journal (OROAJ)}

(68.6\% vs $13.7 \%$ : 0.001 ), the other surgically interventions significantly reducing the death rate. With sensitivity of $82 \%$ and a specificity of $70 \%$, the surgical intervention is a good predictor of survival (AUC= 0.763; IC95\%: 0.668-0.857).

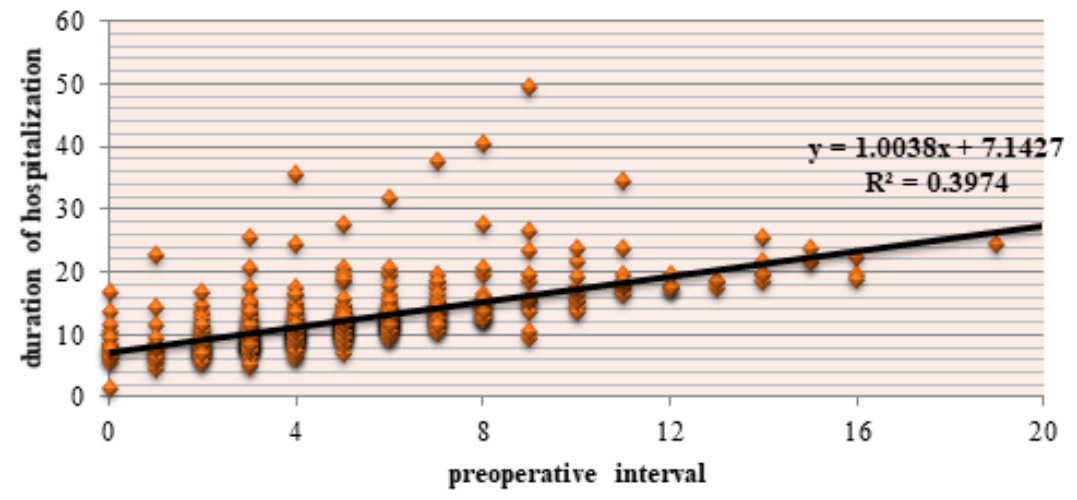

Figure 5: Correlation between the preop period and the duration of hospitalization.

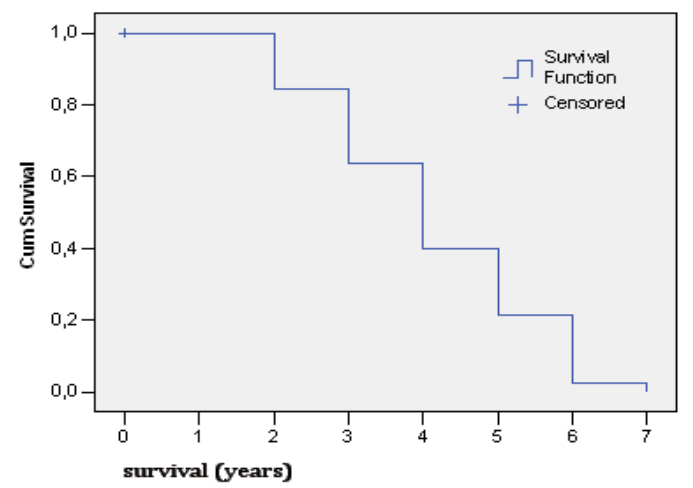

Figure 6: The Kaplan-Meier curve - the probability of postoperative survival.

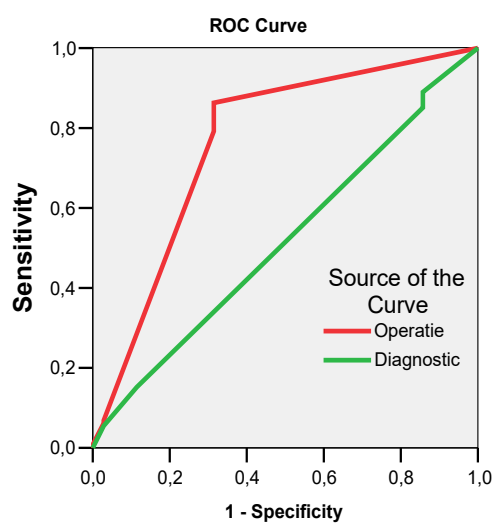

Figure 7: The sensitivity/specificity balance of the surgical intervention and diagnosis in determining a favorable prognosis.

\section{Discussion}

This study aims at an epidemiological characterization of the EFPF at the level of Iasi county, between January 2017 - December
2019. At a European level, the EFPF incidence is heterogenous, most countries falling in the high and average incidence group. Romania, beside Croatia, shows the lowest incidence of these 
fractures. Despite the large number of epidemiological studies regarding EFPF in the world, in Romania there is a scarcity of studies with regard to EFPF in the Eastern part of the country. "St. Spiridon" Clinical Emergency Hospital is the largest emergency hospital in Moldova, so that we can state that the number of admissions in the orthopedics-traumatology clinic reflect accurately the incidence of these fractures at the level of Iasi county. The epidemiological profile of the patients in the study lot was not different from that in the specialized literature. Thus, the patients' average age was 76 , similar to the age reported in the literature: 75 years old, according to Adam [6], 78.2 according to Hungria et coll. [7], namely 79.6 according to Ramalho [8].

We identified a prevalence of the female gender among the EFPF patients. The gender ratio was $1.8 / 1$ in favor of the female gender, significantly higher than in the Western side of Romania in the same period, where the ratio was of $1.39 / 1$ [1], however close to the 1.72/1 ratio identified by Grigorie at the national level for 2010 [5]. He identified a fracture risk of 7\% for women and of only $3.8 \%$ for men. This tendency was also identified by other authors [9-18], who identified a gender ratio of 3:1 in favor of the female gender. The proportion among the identified subtypes was not uniform, $91 \%$ of all fractures being represented by pertrochanteric fractures, $2 \%$ basicervical and inter-trochanteric fractures and only $1 \%$ sub-trochanteric fractures, avulsion fractures and complex trochanteric fractures. Other authors reported proportions of up to $50 \%$ for pertrochanteric fractures $[8,19]$. Due to the anesthetic and surgical risks and the patient's/ family's personal option, the functional treatment was used in $13.8 \%$ of the cases, a high percentage in relation to the data presented in the literature, which report values around 5\% [19].

The preop period varied between 1 and 19 days, without significant differences of the mean values recorded on types of fractures $(p=0.355)$, with a mean value of 7 days, similar to the value met in the South-American population [19] but higher than those reported in the US and Western Europe, explained by the poor clinical conditions of the patients at the moment of admission, which required a delay in the surgical intervention. This was positively correlated with the duration of admission, $y=1.0038 x+7.1427, p=0.001$. The duration of hospitalization varied between 1 and 49 days, with significant differences of the mean values registered depending on the diagnosis $(p=0.001)$, with a mean value of 11 days, which is similar to the one recorded in the literature, of $7.2-13.5$ days $[19,20]$. The longest duration of hospitalization was registered in case of patients with pertrochanteric fractures, also motivated by the fact that the proportion of these fractures was of $91 \%$. The avulsion fractures represented the shortest hospitalization, due to the fact that in their case a functional treatment was preferred, only one out of 12 cases requiring surgical treatment. In Romania, the risk of death in case of extracapsular fractures is 1.359 times higher compared to intracapsular fractures [1], the mortality at 1 year postop being of $21.1 \%$. We failed to identify data in the literature regarding intrahospital mortality in case of EFPF in Romania.

In the study lot, we identified an intrahospital mortality rate off $4.48 \%, 1.55 \%$ among operated patients, namely $10.12 \%$ among patients with functional treatment, a lower value compared to the data reported by Poenaru [1], by the studies from the SouthAmerican continent - 7-9\% [8,19,21,22], but higher compared to the North-American continent - $2-3 \%[3,4,20]$. The deceased patients were mainly female patients (66.7\%), explained by the fact that the gender ratio in the study lot was 1.8/1. At the same time, the presence of osteoporosis associated to the old age of the female gender population and the absence of its diagnosis and treatment determined the presence of pertrochanteric, complex trochanteric and trochanteric - diaphyseal fractures at older ages and avulsion or basicervical fractures at younger ages.

We failed to identify statistically significant differences regarding the patients' survival depending gender and diagnosis, the most frequent deaths belonging to the 80-89 age group. This study has a series of limitations. It is a retrospective study, obtained exclusively based on UICS and GCOS data. The number of patients largely reflects the epidemiological condition at the level of Iasi county, but fails to include patients admitted for EFPF treatment in other hospitals. The study lot comprises patients both from the urban and rural environments, most studies identified in the literature failing to classify patients according to their origin environment.

\section{Conclusion}

In the North-East of Romania, EFPF affect most frequently female patients coming from the rural environment, aged 65 and above, mostly between 80 and 89 . The complexity of the fractures is correlated with the patients' age and the origin environment. Surgically treated patients show a better intrahospital survival rate than functionally treated patients. Intrahospital mortality is higher among the female patients coming from the rural environment, aged between 80 and 89. A series of factors, such as male gender and an age group above 70, due to the high frequency, were good predictors of death and the urban environment generated an estimated risk of postoperative death increased by over 3 times.

\section{References}

1. Poenaru DV, Prejbeanu R, Iulian P, Horia Haragus, Emilian Popovici, et al. (2014) Epidemiology of osteoporotic hip fractures in Western Romania. Int Orthop 38(11): 2329-2334.

2. Ooi LH, Wong TH, Toh CL, H P Wong (2005) Hip fractures in nonagenarians-a study on operative and non-operative management. Injury 36(1): 142-147.

3. Novack V, Jotkowitz A, Etzion O, Avi Porath (2007) Does delay in surgery after hip fracture lead to worse outcomes? A multicenter survey. Int J Qual Health Care 19(3): 170-176. 
4. Simunovic N, Devereaux PJ, Sprague S, Gordon H Guyatt, Emil Schemitsch, et al. (2010) Effect of early surgery after hip fracture on mortality and complications: systematic review and meta-analysis. CMAJ 182(15): 1609-1616.

5. Grigorie D, Sucaliuc A, Johansson H, John A Kanis, Eugene McCloskey (2013) Incidence of hip fracture in Romania and the development of a Romanian FRAX model. Calcif Tissue Int 92(5): 429-436.

6. Adam P (2014) Treatment of recent trochanteric fracture in adults. Orthop Traumatol Surg Res 100(1 Suppl): S75-83.

7. Hungria Neto JS, Dias CR, Almeida JDB (2011) Características epidemiológicas e causas da fratura do terço proximal do fêmur em idosos. Rev Bras Ortop 46(6): 660-667.

8. Ramalho AC, Lazaretti-Castro M, Hauache O, J G Vieira, E Takata, et al. (2001) Osteoporotic fractures of proximal femur: clinical and epidemiological features in a population of the scity of São Paulo. São Paulo Med J 119(2): 48-53.

9. Alexa O (2003) Fracturile extremității femurale superioare. Iași: Editura Junimea, pp.184.

10. Boufous S, Finch CF, Lord SR (2004) Incidence of hip fracture in New South Wales: are our efforts having an effect? Med J Aust 180(12): 623-626.

11. Brauer CA, Coca-Perraillon M, Cutler DM, Rosen AB (2009) Incidence and mortality of hip fractures in the United States. JAMA 302(14): 1573-1579.

12. Court-Brown CM,Heckman JD,McKee M, et al. (2015) Rockwood and Green's Fractures in Adults $8^{\text {th }}$ Ed, Philadelphia: Wolters Kluwer Health.

13. Dhanwal DK, Cooper C, Dennison EM (2010) Geographic Variation in Osteoporotic Hip Fracture Incidence: The Growing Importance of Asian Influences in Coming Decades. J Osteoporos 2010: 757102.
14. Hagino H, Katagiri H, Okano T, Kichizo Yamamoto, Ryota Teshima (2005) Increasing incidence of hip fracture in Tottori Prefecture, Japan: trend from 1986 to 2001. Osteoporosis International 16(12): 1963-1968.

15. Leslie WD, O’Donnell S, Lagacé C, P Walsh, C Bancej, et al. (2010) Population-based Canadian hip fracture rates with international comparisons. Osteoporos Int 21(8): 1317-1322.

16. Moayyeri A, Soltani A, Larijani B, M Naghavi, F Alaeddini, et al. (2006) Epidemiology of hip fracture in Iran: results from the Iranian Multicenter Study on Accidental Injuries. Osteoporosis International 17(8): 1252-1257.

17. Povoroznyuk VV, Grygorieva NV, Kanis JA, McCloskey EV, H Johansson, et al. (2017) Epidemiology of hip fracture and the development of FRAX in Ukraine. Arch Osteoporos 12(1): 53.

18. Riera-Espinoza G (2009) Epidemiology of osteoporosis in Latin America 2008. Salud Pública de México 51(supplement 1): S52-S55.

19. Daniachi D, Netto Ados S, Keiske N, Rodrigo Pereira Guimarães, Giancarlo Cavalli Polesello, et al. (2015) Epidemiology of fractures of the proximal third of the femur in elderly patients. OnoRev Bras Ortop 50(4): 371-377.

20. Bentler SE, Liu L, Obrizan M, Elizabeth A Cook, Kara B Wright, et al. (2009) The aftermath of hip fracture: discharge placement, functional status change, and mortality. Am J Epidemiol 170(10): 1290-1299.

21. Sakaki MH, Oliveira AR, Coelho FF, Luiz Eugênio Garcez Leme, Itiro Suzuki, et al. (2004) Estudo da mortalidade na fratura do fêmur proximal em idosos. Acta Ortop Bras 12(4): 242-249.

22. Siqueira FV, Facchini LA, Piccini RX, Elaine Tomasi, Elaine Thumé, et al. (2007) Prevalence of falls and associated factors in the elderly. Rev Saúde Pública 41(5): 749-756.

\section{Your next submission with Juniper Publishers will reach you the below assets}

- Quality Editorial service

- Swift Peer Review

- Reprints availability

- E-prints Service

- Manuscript Podcast for convenient understanding

- Global attainment for your research

- Manuscript accessibility in different formats ( Pdf, E-pub, Full Text, Audio)

- Unceasing customer service

Track the below URL for one-step submission https://juniperpublishers.com/online-submission.php 